\title{
Primary recovery of miraculin from miracle fruit, Synsepalum dulcificum by AOT reverse micellar system
}

\begin{abstract}
Miracle fruit, Synsepalum dulcificum, contains a glycoprotein known as miraculin. After consuming this glycoprotein, sour foods taste sweet and the effect lasts for up to $4 \mathrm{~h}$. With increasing demand for natural and "low-calorie" sweeteners, the use of miraculin as an additive is increasing enormously in the food, medicine and cosmetic industries. In this study, we used reverse micelles formed from a sodium di (2-ethylhexyl) sulfosuccinate (AOT)/isooctane system to purify miraculin from S. dulcificum. We studied factors affecting purification performance, such as surfactant (AOT) concentration and the $\mathrm{pH}$ of the crude during forward extraction. During backward extraction, we examined the effects of $\mathrm{NaCl}$ concentration, the $\mathrm{pH}$ of the aqueous phase and addition of isopropanol. We found that 0.1 $\mathrm{mol} / \mathrm{L}$ AOT/isooctane solution mixed with crude extract at $\mathrm{pH} 8$ during the forward extraction stage and $0.5 \mathrm{~mol} / \mathrm{L} \mathrm{NaCl}$ solution at $\mathrm{pH} 11$ during the backward stripping stage were optimal purification conditions, from which $22 \%$ miraculin was recovered with a purity of $94.8 \%$.
\end{abstract}

Keyword: Reverse micelles; Surfactant; Liquid-liquid extraction; Separation; Purification 